\title{
Integrated, Consolidated or Specialized Financial Markets Supervisors: Is there an Optimal Solution?*
}

\author{
Jan Monkiewicz \\ Insurance \& Pension Funds Supervisory Commission, 6 E Niedzwiedzia Street, PL - Warsaw 02-737, \\ Poland. \\ E-mails: jan.monkiewicz@knuife.gov.pl, Elzbieta.Magdziak@knuife.gov.pl
}

The article discusses the issue of the financial market supervision in its institutional context and explores its various dimensions. Its intention is to review the origins and directions of institutional restructuring of the supervision taking place in the last 15 years and to discuss its opportunities and threats. The actual debate is preceded by an analysis of recent financial market trends as well as regulatory and supervisory developments. The message of the article is that there are no ideal supervisory models and each jurisdiction has to find its own way. In doing so, it should always care for the preservation of the most critical properties of the supervisory system: its independence, accountability, transparency, integrity and market responsiveness.

The Geneva Papers (2007) 32, 151-162. doi:10.1057/palgrave.gpp.2510109

Keywords: supervision; consolidated supervision; insurance regulation; supervisory process; supervisory models

\section{Introduction}

The dramatic growth in the importance of the financial markets over the last decades for the economic well-being of nations has generated rapidly an increasing body of literature on various aspects of regulation and supervision. This literature covers such issues as scope and size of regulation and supervision; its benefits and costs; the respective roles of regulation and self-regulation; aims and tools of regulatory and supervisory activities; the components of regulatory and supervisory layout; the interplay between regulation and supervision; and cross-border regulatory and supervisory cooperation and the like.

Most recently, particular attention has been given to the institutional aspects of financial regulation and supervision. This reflects recent changes taking place in several countries in the institutional set-up of financial markets regulation and supervision and the need for the clarification of its drivers as well as its consequences. In particular, the convergence of specialized sectoral supervisors in banking, insurance and securities into more or less integrated regulatory and supervisory agencies has been by and large put through as political rather than economic or managerial projects.

\footnotetext{
* The paper is an outcome of a lecture presented at the 22nd Progress International Seminar, held on 30-31st March, 2006, in Geneva.
} 
Increased emphasis in the current debate is given to the question of the possible impact of the particular institutional structures on the efficiency of regulation and supervision in achieving their major objectives.

The intention of the present paper is to review major issues of the above discussion of the topic and to offer some analytical framework for further debate. The paper starts with a presentation of some major market trends in the financial sector, which are the final drivers of the regulatory and supervisory changes. It is followed by a brief review of regulatory and supervisory trends. The next section discusses the notion of an integrated supervisor and examines various directions and degrees of integration. It is followed by an assessment of the drivers of supervisory integration as well as its constraints. Finally, the potential rewards and costs of integration are discussed.

\section{Financial market trends}

Over the last decades financial services and financial markets have been growing dynamically in all parts of the world, thus confirming their fundamental role in the current economy. By the end of 2004 the world total of financial assets was estimated at USD152 trillions, of which 37 per cent were accounted for by EU, 31 per cent by the United States and 14 per cent by Japan. ${ }^{1}$ The value of these assets exceeds significantly GDP level in the world (369.2 per cent), EU (457.8 per cent), U.S. (460.6 per cent) and Japan (467.2 per cent). In Luxembourg, the value of the financial assets surpasses national GDP by 25 times.

Particular growth drivers of the financial market in recent years have been, increasingly, institutional investors that have taken over the lead from a traditional banking industry. As of 2004, bank assets accounted only for around one-third of the world total financial assets and in the United States only for about 18 per cent of the total. In the EU, this share was substantially higher; however, it has decreased in recent years.

In OECD countries alone, institutional investors managed in 2003 financial assets of a value close to USD 47 trillions, representing roughly 160 per cent of their GDP. They are spread evenly between insurance companies (about USD14.5 trillions in 2004) pension funds (USD15.3 trillions in 2004) and investment companies (USD16.2 trillions in 2004). Hedge funds play still a minor role, representing roughly only USD0.9 trillions in 2004 (see Table 1).

Altogether, assets managed by institutional investors nearly tripled in 1990-2004. Particular dynamic growth in 1990-2004 was recorded in the assets managed by investment companies and hedge funds. Pension funds preserved their relative position on the market. On the other hand, there was some downgrading as institutional investors of the insurance companies.

Institutionalization of the financial market investments coincides with a growing size and role of household financial assets. According to the U.S. market data, roughly 50 per cent of U.S. households held in 2005 mutual fund products as opposed to only

\footnotetext{
${ }^{1} \operatorname{IMF}(2006$, p. 155).
} 
Table 1 Assets under management by institutional investors in OECD countries (in trillions of USD)

\begin{tabular}{|c|c|c|c|c|c|c|}
\hline & & 1990 & 1995 & 2000 & 2003 & 2004 \\
\hline 1. & Insurance companies & 4.9 & 9.1 & 10.1 & 13.5 & - \\
\hline 2. & Pension funds & 3.8 & 6.7 & 13.5 & 15.0 & 15.3 \\
\hline 3. & Investment companies & 2.6 & 5.5 & 11.9 & 14.0 & 16.2 \\
\hline 4. & Hedge funds & 0.03 & 0.10 & 0.41 & 0.80 & 0.93 \\
\hline 5. & Total institutional investors & 13.8 & 23.5 & 39.0 & 46.8 & - \\
\hline 6. & Investment/GDP (per cent) & 77.6 & 97.8 & 152.1 & 157.2 & - \\
\hline
\end{tabular}

Source: Global Financial Stability Report, September 2005 p. 67.

about 6 per cent in 1980 and 25 per cent in 1990. Mutual funds' share of household financial assets has climbed up from 6.8 per cent in 1980 to 20.3 per cent in $2005 .^{2}$

Enhancement of the financial market and its institutionalization is paralleled by its growing concentration and internationalization. According to the U.S. data, the top five banking companies in this country increased their domestic deposits share from 8 per cent in 1990 to 21 per cent in 2001, whereas the share of the top 25 banking companies climbed up from 25 per cent to 45 per cent, respectively. ${ }^{3}$ The top 10 global insurance companies assumed over 26 per cent of the world premiums in 2004, whereas the respective share of the 10 global life/health insurance companies in worldwide premiums exceeded 30 per cent. ${ }^{4}$ A much higher concentration ratio is traditionally observed in the reinsurance business. Data for 2004 suggest that over 75 per cent of the worldwide premium ceded was assumed by the top 10 global reinsurers. It is a widely held belief that in principle a few hundred financial groups currently dominate the world market. The same groups are by and large responsible for the growing globalization of the market place. Its degree could be judged from the figures related to the EU market. They indicate that the role of foreign investors in the financial business assumed in the region increased from about 10 per cent in the early 1990 s to around $25-30$ per cent in 2003-2004. ${ }^{5}$

The same groups are also the principal drivers of the spread of conglomerates in the financial market. Their market share has been rapidly increasing since the beginning of the 1990s. The EU Commission Services estimate that, as a weighted average, financial conglomerates account for approximately 30 per cent of the deposits and 20 per cent of premium income in EU 15 member states. In the smaller ones, their market share exceeds even 50 per cent. ${ }^{6}$ According to some other estimates, their share may be even higher. $^{7}$

The growth of financial conglomerates reflects the blurring of the existing intersectoral borders and provides for the rise of cross-sectoral business offer or to put it in a different way - product hybridization. As a result, integrated financial

\footnotetext{
2 Antoniewicz (2006, p. 7).

${ }^{3}$ Kapstein (2006, p. 17).

${ }^{4}$ Insurance Information Institute (2005).

${ }^{5}$ Financial integration monitor (2005).

${ }^{6}$ Financial integration monitor (2004, p. 19).

${ }^{7}$ Luna Martinez and Rose (2003, p. 10).
} 
institutions are offering bundled and integrated financial products, frequently via integrated distribution channels.

\section{Current regulatory trends}

Financial services and financial markets are traditionally subject to public regulation. Frequently, they are also subject to private regulation - voluntary regulation which, in some cases, can substitute for public intervention. This regulation has its long history going back to the 19th century. Insurance regulation, for example, was first introduced in the United States - in New York and Massachusetts - already in the 1860s. It was followed by The U.K. Life Assurance Act of 1870. The American regulation was very tight, demanding the close scrutiny of insurance contracts and prior approval of premium rates. The British one, on the contrary, was restricted to life insurance only and was based on the principle of "freedom with publicity".

The two regulations thus represented two extreme models of public intervention into the business activities of the financial institutions, which has continued since then throughout the centuries. They also illustrate the major dilemma public authorities are facing until today, as to the role of regulation and the market forces or "freedom", respectively.

In the last 15 years, some fundamental changes in financial regulation have taken place. Most important probably has been the concentration of the financial sector regulatory activities in one single place. This was in most instances the ministry of finance that has taken over the duties from various other administrative bodies.

The next important development was a shift towards separation of regulatory and supervisory authorities: the first one being basically responsible for introducing rules and principles, and the second one for putting them into practice.

A characteristic feature of regulatory developments during the last 15-20 years is the enhanced coverage of public regulation and a tendency towards the limitation of the role of self-regulatory institutions. The best illustration is probably the history of Lloyds, which - after centuries of self-regulatory independence - has finally recently been subordinated to the U.K. Financial Services Authority. Taking insurance as an example, this enhanced coverage includes issues such as reinsurance, intermediation, outsourcing, corporate governance, suitability of persons, intra-group relationships and the like. Additionally, this enhanced coverage is accompanied by the expansion of the existing financial safety nets, inter alia, via the development of some guarantee systems used against financial institution failures.

Finally, one should draw attention to the accelerated convergence of regulatory and supervisory standards both cross-sectorally and across the countries, and the special role played in this regard by the global supervisory organizations: IAIS, Basel Committee and IOSCO.

\section{Current supervisory trends}

Financial supervision is a twin brother of regulation; hence, it basically follows the fortunes of the latter. From the supervisory point of view, the most critical 
development in recent years was its separation from the regulatory activities. It allowed not only for its necessary specialization and adequate resourcing - difficult to imagine in the existing administrative framework - but, above all, it also provided for the political and decision-making independence by cutting it from the unduly interference of the government machinery. Today, this supervisory independence has become a mandatory and self-evident element of modern supervisory systems, and is one of their classical attributes, along with such attributes as their accountability, integrity and transparency.

Supervision has been for a long time principally concerned with compliance tracking. Financial institutions were supposed to behave according to the regulatory requirements, and the role of supervisory authorities was to simply check their compliance. In the 1990s, however, financial supervision became more and more concerned with risk detection, management and control. Dynamic risk-oriented supervision is thus replacing currently the old-fashioned and static complianceoriented one. Logically, this leads to a shift from a retroactive to a proactive supervisory approach, and a necessary change of supervisory tool-kit in use.

With the growing globalization and integration of the local financial markets these changes are, additionally, supplemented by the convergence of the supervisory models, standards as well as policies, both across sectors as well as across countries. Thus, for example, Basel II sets the scene for Solvency II, and the American risk-based supervision and EU Solvency II set precedence for a new IAIS solvency concept, etc.

Traditionally, supervision was organized around individual financial sectors: banking, insurance and securities. In the late 1990s, however, more and more jurisdictions started to consolidate their supervisory structures. By mid-2006, out of 99 countries supervising three sectors (banking, insurance and securities), 31 of them had fully integrated supervisory agencies, whereas 44 of them continued to have multiple or fragmented supervisors. Eleven countries decided to pull together their banking and insurance supervisors, eight of them consolidated securities and insurance and the remaining five consolidated banks and securities, the latter appearing to be the leastpreferred option. ${ }^{8}$

Particular acceleration of the integration projects has taken place during the last five years (Table 2).

It clearly seems to be a currently winning option in all major world financial markets - Japan, Australia, Canada and particulary Europe - with the notable exception of the United States, which continue with their highly fragmented and sectorally focused supervisory system.

\section{What is an integrated supervisor? The concept of an integration ladder}

As always a new phenomenon leads to some confusion among its analysts as to its real meaning. The same applies to the notion of an integrated supervisor. An open question until today remains its practical understanding. Interestingly enough,

\footnotetext{
${ }^{8}$ World Bank (2006).
} 
The Geneva Papers on Risk and Insurance - Issues and Practice

156

Table 2 Establishment of fully integrated agencies

\begin{tabular}{llll}
\hline Year & Country & Year & Country \\
\hline 1978 & Singapore & 2002 & Austria \\
1981 & Maldives & 2002 & Estonia \\
1983 & Norway & 2002 & Germany \\
1987 & Canada & 2002 & Hungary \\
1988 & Denmark & 2002 & Malta \\
1991 & Sweden & 2003 & Ireland \\
1997 & Korea & 2004 & Belgium \\
1998 & Australia & 2004 & Kazahstan \\
1998 & Japan & 2004 & Netherland \\
1998 & United Kingdom & 2006 & Czech Republic \\
1999 & Iceland & 2006 & Poland \\
2001 & Latvia & 2006 & Slovak Republic \\
\hline
\end{tabular}

Source: Demaestri E., Sourrouille D., Integrated Financial Supervision: Experiences in selected countries, Inter-American Development Bank, Washington D. C. 2003 p. 2 and own research.

however, in the existing literature this issue is practically not covered and it seems to be a unanimously accepted view that "integrated" means cross-sectoral, that is, covering various financial sectors and various financial institutions. If one, however, investigates the matter more closely, this view could easily be challenged. It could be claimed that at least two different dimensions of supervisory integration might be identified: its breadth and its depth.

Breadth of the supervision is defined by its sectoral and/or functional coverage. From this perspective, one could note on the one hand fragmented or mulitipillar supervision, covering individual or partially bundled financial sectors, conventionally split into banking, insurance and securities. On the other hand, there is a cross-sectoral or integrated financial market supervision, represented by a unique supervisory institution.

There is, however, another, equally important perspective, which is largely absent in the analysis up to now - that is a functional one. The functional perspective starts from the observation that there are a variety of supervisory functions and its constituent elements are licensing, on-going supervision, enforcement, prudential, market conduct supervision, etc. (see Figure 1). They all remain inherent parts of the supervisory system; however, they could be placed under the administration of separate bodies. One frequently overlooks in the current debate that integration of supervisory functions in recent years has covered also integration under one roof of licensing and on-going supervision, as well as prudential and market conduct activities for the entirety of the financial market. These other integration dimensions could have, as a matter of fact, much more profound effects for the supervisory efficiency and effectiveness than those limited to the only organizational ones.

As to the depth of the supervisory integration one could identify at least three levels of the integration projects: institutional, technical and organic. Institutional integration is basically confined to the organizational unification of the supervisory authority, with some minor internal shake ups, which might include eliminating some 


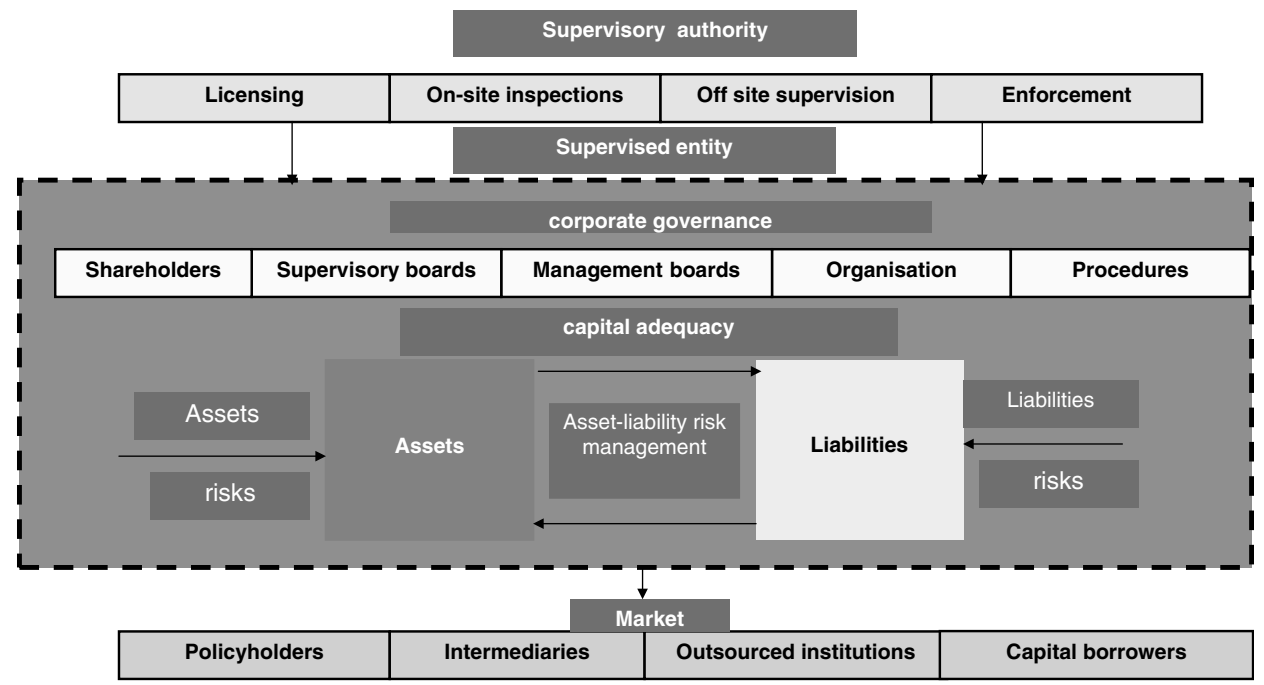

Figure 1. Principal elements of supervisory process.

interfering organizational units or adding some others to cover new responsibilities. It is de facto more a consolidation than real integration.

Technical integration on the other hand assumes unification or at least convergence of the supervisory tool-kits used, such as models, processes and policies. It is more painful and complex in comparison to the formal institutional integration and requires much more effort to be completed. Therefore, it is also more common in the current integration drive to avoid any substantial technical integration, at least in the first phase.

The same is even more true with regard to organic integration, which includes unification of the regulatory rules, principles and standards, thus providing for the single legal framework. For these reasons, this level of supervisory integration remains quite rare and the most seldom-used option of all registered integration projects.

\section{What are the drivers and constraints of the supervisory integration?}

The spread of "integrated" supervisory systems, basically meaning the proliferation of institutional cross-sectoral consolidation, reflects in principle the search by individual jurisdictions for more efficiency and effectiveness in the supervisory activities in a period of increasing complexity of the financial system. This search, however, has had - as a rule - different individual triggers in different countries. In some of them - and this seems to be the most natural - it was an unsatisfactory performance of the existing mulitipillar, fragmented supervision. It is always best tested during a financial crisis, which usually uncovers all the hidden weaknesses of the supervisory system in place. It was precisely for that reason that Korea, Japan and Australia shifted from mulitipillar to consolidated supervision, after experiencing financial failures of some of their big 
financial institutions. Incidentally, crisis experience has always been until today accompanied also by frequently sweeping regulatory changes. The Sarbanes-Oxley Act of 2002 is probably the best living example of what the regulatory power of big financial failures today is.

Sometimes supervisory institutional integration was a direct answer to the excessive level of the supervisory fragmentation. This was apparently an important argument for the reform of the financial supervision in the United Kingdom, where there were nine specialized financial supervisory institutions in 1998 when the decision on merging them into the Financial Services Authority was undertaken. ${ }^{9}$

In some instances, integration of supervisory institutions responds to national market developments, in particular to its conglomeration. As indicated before, current market structures are frequently characterized by the emergence of complex financial conglomerates. If this happens, it naturally calls for the supervisory structures able to match their complexity. An excellent example is provided by the Dutch experience where recent institutional consolidation of the supervisory structures came into effect mainly due to the spread of national financial conglomerates. ${ }^{10}$ According to available statistics, they represented in 2004 about 60 per cent of the national banking and insurance assets. There were therefore strong market arguments favoring supervisory integration.

Integration of the supervisory institutions may also result from the increased pressure on the available supervisory resources. By its nature, it is more common in small than large jurisdictions. This explains why small countries are at the forefront of the supervisory integration. They simply may have no choice but to pool their scarce supervisory resources together to match market demands.

Finally, supervisory integration may have its roots in the regulatory integration, which creates strong demand for the single supervisory partner that could balance its powers and provide more equilibrium to the financial system.

Last but not least supervisory integration may also reflect the spread of the demonstration effect across the countries that are willing to imitate solutions adopted in their benchmarking jurisdictions.

On the other hand, there are also strong constraining factors of the integration projects. They include first of all traditional separation of the financial market regulatory base and hence separation of the supervisory competences. They include further different supervisory goals of the main sectoral supervisors. The Basel Committee for example defines the major goal of banking supervision as: "to ensure that banks operate in safe and sound manner and that they hold capital and reserves sufficient to support the risks that arise in their business". IAIS, on the other hand, declares that the role of insurance supervision is "to maintain efficient, fair, safe and stable insurance market for the benefit and protection of policyholders". IOSCO requests from supervision "investors' protection, ensuring fair, efficient and transparent markets and reduction of systemic risk". Thus, banking supervision is

\footnotetext{
${ }^{9}$ Briault (1999, p. 6)

${ }^{10}$ Witteeven (2006).
} 
principally concerned with systemic stability, whereas insurance supervision is more about consumer protection and securities about investors' protection.

Another constraint that arises from these differences is the business and risk profiles of the supervised institutions. Banks suffer primarily from the insufficient quality of their assets, whereas insurers clearly depend more on the quality of their liabilities. Investment companies on the other hand are mainly hurt by their market misbehavior. To bring all these different considerations under one roof is not an easy task for the integrated supervisor.

Last but not least some role in constraining supervisory integration is played by the existing sectoral structure of international standard setters that - in spite of a growing cooperation - continue to produce standalone standards and rules addressed to individual financial sectors.

\section{What are the potential rewards of the integrated financial supervision?}

An integrated supervision has a number of potential advantages that, however, contrary to what some people could think, are not emerging automatically and unconditionally.

It undoubtedly allows for better understanding of cross-sectoral risks and issues and improved oversight of complex financial institutions. The more "interwoven" a financial system in a given jurisdiction and the greater the role of financial groups and conglomerates in there, the more arguments exist for a unified financial supervision. This is particularly the case when these groups themselves apply a centralized approach to risk management and risk taking. ${ }^{11}$ Having all supervisory powers under one roof, an integrated supervisor is able to better catch the problems of such complex organizations. It can also better match their institutional powers and thus better defend its own independence.

An integrated supervisor will also more likely achieve the situation in which there are similar rules for similar activities across all segments of the financial system and therefore the possibilities of regulatory arbitrage are eliminated or at least limited. As a result, a more level playing field across various financial sectors and various financial institutions can be installed. Integration of supervision should additionally eliminate the danger of accountability diffusion particulary in cases of regulatory failures. It can also provide for better communication, coordination and cooperation among different supervisory departments and officers, thus increasing the operational efficiency of the organization.

An important argument in favor of the integrated supervision is related to the potential economies of scale. This could be achieved through centralized regulatory functions leading to the development of joint support functions such as administration, information technology, accounting, legal services, etc. This could be additionally reinforced with respect to the better use of qualified people and other scarce resources as well as the optimal staff deployment within the integrated organization. Potential

${ }^{11}$ Llewellyn (2006, p. 18). 
economies of scale may be particulary relevant for small countries where expertise in supervision is in short supply, less for big economies. In both cases, however, a bigger and stronger agency may seem to offer better career prospects and may thus be more able to attract better people.

Finally, integrated supervision also offers potential economies of scope (synergies) via diffusion of best supervisory tools and practices from individual supervisory institutions.

\section{What are the potential hazards of the integrated supervision?}

It is interesting to note that so far proactive decisions on restructuring of financial supervision - at least in Europe - have been in most cases delivered as political initiatives and, as such, never preceded by wide expert discussions. Only in cases of retroactive actions - following financial crisis - have public debates come usually to play an important role.

There are in principle four groups of concerns related to the transition from fragmented to integrated supervision that in the end may jeopardize the whole idea and question its rationality. Generally speaking, it will happen when the costs of changing the existing structures outweigh the benefits of an integrated supervisor. It should be stressed at the same time that other things being equal, however, the success of an integrated supervision is highly dependent upon the strengths of its predecessors. The old principle "rubbish in - rubbish out" maintains its full validity also in consolidation attempts. We should also underline that the integration process should be carried out only in a time of stability of the financial system. ${ }^{12}$

The first concern about the integrated supervision is about the temporal deterioration of market supervision at the time of transition from multiple supervisory architectures to a single one. It is quite natural that merging existing institutions leads to the major reorganization of its functions, roles and policies and creates a feeling of increased uncertainty among staff members and loss of momentum. ${ }^{13}$ Some officers with vital skills may leave the services and seek other career opportunities, thus increasing the likelihood of the organizational disruption.

The creation of a single supervisor may also involve a loss of valuable information due to the application of an integrated approach or simply due to the loss of critical staff. As indicated by some researchers, this period of lowered organizational efficiency may last up to two years, depending on the conditions in individual countries. ${ }^{14}$

It is an important variable therefore in the decision on timing of the restructuring operation. It should avoid to the maximum extent possible a situation in which existing sectoral supervisors are already under fire from current challenges that need to be promptly and efficiently resolved or in market turbulences.

\footnotetext{
12 Siregar and Williams (2004, p. 7).

${ }^{13}$ Fiechter (2006).

14 Luna Martinez and Rose (2003).
} 
The second group of concerns is even more serious, as there is a possibility that in the long-term integrated supervision will be less effective and efficient than its sectoral predecessors. This situation may result both from the improper or premature merging as well as from the inadequate staffing and resourcing of the new institution or else from its poor management. As in any consolidation project there is a potential danger of lowering the market value of the new consolidated institution instead of increasing it.

The third group of concerns relates to the risk of bureaucratic inefficiency of a single institution, unable to differentiate its tools and approaches and to rapidly respond to market failures. There is a danger that within such a big cross-sectoral institution, necessary differences between different financial institutions are not taken care of and a tendency towards a unified approach will dominate. Critically important in particular is supervisory responsiveness and innovativeness to keep pace with financial market trends and developments.

Finally, the fourth concern is about the risk of eliminating the existing checks and balances in the supervisory structure system and excessive concentration of power in one single authority. It is therefore of utmost importance to ensure an adequate system of political control and rules of political accountability of the newly created institution.

\section{Some conclusions}

As we have seen from the foregoing analysis, there are many alternative supervisory models that could be chosen by national jurisdictions. There are also a variety of "fragmented" and "integrated" solutions. Institutional consolidation is only one possible measure to improve market supervision. Although it may not be necessarily the most critical one, at the same time its importance should not be overlooked. Different structures may have different implications for the costs of supervision. They may also impact on the overall effectiveness of supervision via its differentiated mandate (focused or diversified) and coverage.

It is important to stress that chosen models of supervisory architecture should reflect local circumstances and should always be made to measure. The selection process is particularly burdensome if the country is not starting its supervision from the scratch but has some supervisory institutions already in place. As a matter of fact, this is exactly the dilemma that policymakers are facing in a real world. A question then to be addressed would be, what is a more optimal solution: fine tuning or fundamental restructuring? A fundamental issue in particular to be considered is the role of the central bank in the supervisory context, especially in bank-based financial systems.

Finally, it should be underlined that when undertaken, integration projects should properly take account of timing, duration, pace of integration process and governance aspects of the new institution. Otherwise transaction costs may eat all potential benefits of the new institutional layout.

\section{References}

Antoniewicz, R. (2006) Overview of the U.S. Mutual Fund Industry (April 19), Securities and Exchange Commission, Washington, DC. 
Briault, C. (1999) The rationale for a single national financial services regulatory, Occasional Paper Series 2 , FSA (May).

Fiechter, J.L. (2006) Aligning supervisory structures with country needs, Remarks at the World Bank/IMF Global Conference, Washington, D.C. (June 5).

IMF (2006) Global Financial Stability Report (April), Washington, DC.

Insurance Information Institute (2005) International Insurance Fact Book, New York: III.

Kapstein, E.B. (2006) Architects of stability? International cooperation among financial supervisors, BIS Working Papers, No. 199 (February), Basel.

Llewellyn, D.T. (2006) Institutional Structure of Financial Regulation and Supervision: The Basic Issues, Paper presented at a World Bank Seminar Aligning Supervisory Structures with Country Needs, Washington D.C. (6-7 June).

Luna Martinez, J.R. and Rose, T.A. (2003) International survey of integrated financial sector supervision, World Bank Policy Research Working Paper 3096 (July).

SEC (2004) Financial integration monitor 2004, Commission Staff Working Document, SEC (2004) 559.

SEC (2005) Financial integration monitor 2005, Commission Staff Working Document, SEC (2005) 559.

Siregar, R.Y. and Williams, J.E. (2004) Designing an integrated financial supervision agency: selected lessons and challenges for Indonesia, Discussion Paper No. 405, CEIS, University of Adelaide, Australia (October).

Witteeven, D. (2006) View of DNB on Supervision 2006-2010, Warsaw (10 March).

World Bank (2006) Supervisory Structures: A Global Overview, Paper Prepared for World Bank Conference on Aligning Supervisory Structures, World Bank (5-6 June, 2006).

\section{About the Author}

Jan Monkiewicz is Professor of Financial Management, Department of Production Engineering, Warsaw Technical University, Warsaw, Poland. From 2002-2006, he has been Chairman of The Insurance and Pension Funds Supervisory Commission in Poland and was a member of the Executive Committee of IAIS during that same period. 